Motrivivência v. 29, n. 50, p. 170-182, maio/2017

\title{
ESPORTE DE AVENTURA COMO CONTEÚDO POSSÍVEL NAS AULAS DE EDUCAÇÃO FÍSICA ESCOLAR
}

Jairo Antônio da Paixão’

\section{RESUMO}

Este estudo investigou possibilidades para o trato das diferentes modalidades que compõem o esporte de aventura como conteúdo da Educação Física na escola. A partir de um levantamento da literatura especializada, fortalece-se a crença de que a busca por elementos com potencial para um currículo escolar alternativo para Educação Física é, acima de tudo, uma atitude de não conformismo, por parte dos atores envolvidos na ação educativa. A própria realidade nas escolas evidencia a necessidade de propostas e movimentos para implementar o processo educacional nos diferentes segmentos que compõem a educação básica. Certamente, a reflexão e o debate sobre a referida temática configuram-se procedimentos fundamentais para que as possibilidades possam ser concretizadas na ambiência das aulas de Educação Física.

Palavras-chave: Escola; Educação Física; Esporte de Aventura

1 Pós-doutor em Educação. Professor da Universidade Federal de Viçosa (UFV). Viçosa/Minas Gerais, Brasil. E-mail: jairopaixao2004@yahoo.com.br 
V. $29, \mathrm{n}^{\circ} 50$, maio/2017

\section{INTRODUÇÃO}

A prática de esporte de aventura é um fenômeno crescente no Brasil nas últimas décadas. Trata-se de práticas corporais, manifestadas no âmbito do lazer e da competição e que, por sua vez, tem como eixos norteadores a aventura, o risco e as fortes emoções em sua máxima intensidade e profusão experienciadas no meio natural.

O esporte de aventura surge a partir de novos paradigmas centrados na (re) aproximação com a natureza, na auto realização, no lazer e na melhoria da qualidade de vida, os quais buscam substituir os de competição, rendimento e esforço pela incerteza, risco e liberdade (COICEIRO, 2007; COSTA, 2000; MARINHO; BRUHNS, 2003; PASSOS, 2004).

O surgimento constante de novas modalidades, acompanhado pelo crescente número de adeptos de diferentes formações culturais, faixas etárias, níveis sociais e campos de atuação profissional, evidencia não somente o seu potencial econômico, como ainda que o esporte de aventura e risco calculado configura-se uma realidade no âmbito atual (MARINHO; BRUHNS, 2003).

Trata-se de práticas físicas inovadoras e diferenciadas, que, ao contrário das modalidades de esportes clássicos, como o vôlei, o basquetebol e o futsal, impõem o esforço gerador da atividade ao atleta. O esporte de aventura se vale das energias provenientes dos elementos da natureza, como vento, ondas térmicas, correntezas, declives de montanha (surf, rafting, canoagem, asa delta, ski, entre outras), ou, ainda, de uma força energética exterior, proveniente de uma máquina motorizada (motociclismo, automobilismo, ultraleve, ski náutico). Assim, por meio de intensa fusão entre o corpo do praticante e a força energética da natureza, torna-se possível a realização de movimento, levando-o a associar sua performance num equilíbrio dinâmico na efetivação da prática de uma dada modalidade de esporte de aventura com êxito (COSTA, 2000).

O quadro até aqui apresentado circunscreve o esporte de aventura como um campo de intervenção profissional docente inovador, instigante e repleto de possibilidades para diferentes âmbitos de ensino e aprendizagem, inclusive o escolar.

Enquanto área de conhecimento e fonte de intervenção social, a Educação Física como componente curricular, consegue dar conta de forma específica e profícua da abordagem de temas que relacionam a práticas corporais ao meio ambiente e à natureza. $\mathrm{O}$ esporte de aventura proporciona ao profissional de Educação Física essa plataforma de trabalho.

Indubitavelmente, a inclusão de novos conteúdos na escola demanda um processo árduo, no qual se faz necessário o rompimento de paradigmas, que se encontram cristalizados na própria história escolar. E nesse processo, a tradição das práticas esportivas seja o mais difícil de ser rompido. Não se pode negar que, na maioria das vezes, os esportes, comumente trabalhados na escola, como aqueles que se inserem na categoria de esportes coletivos, conseguem dar conta de atender ao gosto de uma boa parcela dos formandos da educação básica. No entanto, não se pode desconsiderar que esses alunos devem, e têm o direito, de receber muitos outros conhecimentos presentes na Cultura Corporal de Movimento e assim, aumentar seus conhecimentos, experiências e possibilidades de escolhas. Como afirma Franco (2008), ao se oportunizar aos alunos da educação básica 
informações, conhecimentos e habilidades sobre as práticas corporais na natureza e esportes alternativos aos tradicionais, está-se com isso, aumentando-lhes as opções de uso do tempo disponível já na idade em que se encontram, mas, principalmente, na fase adulta, em que sua liberdade de escolha e independência aumentam significativamente.

Nessa perspectiva, o objetivo do presente estudo foi investigar possibilidades para o trato das diferentes modalidades que compõem o esporte de aventura como conteúdo das aulas de Educação Física tendo em vista as dimensões conceitual, atitudinal e procedimental.

O texto resulta de um levantamento bibliográfico sobre o tema esporte de aventura e sua tematização com possibilidades de seu trato nas aulas de Educação Física na escola.

\section{O ESPORTE DE AVENTURA NAS AULAS DE EDUCAÇÃO FÍSICA}

As diferentes modalidades que compõem o esporte de aventura configuram-se como possibilidades de lazer, turismo, competição e mais recentemente como propostas de temas nas aulas de Educação Física escolar. Há estudos que mostram possibilidades do esporte de aventura em contextos diferenciados e surgem indícios de como podem ser apropriados para serem trabalhadas no âmbito escolar (UVINHA, 2004; CARDOSO et al. 2006; MARINHO; SCHWARTZ, 2008). No entanto, a análise do conteúdo educativo dessas práticas se coloca como pressuposto preliminar de uma proposta que envolva o esporte de aventura como conteúdo nas aulas de Educação Física escolar (MARINHO; SCHWARTZ; LETIZIO, 2001). Vive-se um tempo, a partir da LDBEN n 9.394/96, em que os profissionais da educação dispõem de maior abertura e possibilidades de concretização de propostas pedagógicas inovadores no currículo escolar.

Como eixo norteador da prática docente na escola, os Parâmetros Curriculares Nacionais apontam para a necessidade de se ampliar e enriquecer o conteúdo das aulas de Educação Física escolar através das vivências das diversas manifestações da Cultura Corporal de Movimento, considerando-se as dimensões afetivas, cognitivas, motoras e socioculturais dos alunos (BRASIL, 1998).

A inserção do esporte de aventura na escola justifica-se por meio de várias de suas modalidades. Têm-se, por exemplo, milhões de praticantes de esportes com prancha. Somente na modalidade skate, segundo pesquisa realizada em setembro de 2006 pelo Datafolha, e presente no site da Confederação Brasileira de Skate, há quase 3.200.000 domicílios brasileiros que possuem pelo menos um morador que tem um skate, aproximadamente $6 \%$ dos domicílios brasileiros conforme o IBGE, portanto, são mais de três milhões de praticantes e milhares de competidores, sendo alguns deles campeões mundiais recentemente. Com isso, cada vez mais, ocorre uma popularização desses equipamentos, facilitando seu acesso por pessoas das diferentes camadas sociais (CBSK, 2013; FRANCO, 2008).

O esporte de aventura como conteúdo das aulas de Educação Física escolar surge como possibilidade de novas vivências. Assim, as modalidades marcadas pela tradição da perspectiva tradicional baseada no ensino aprendizagem de técnica e regras de modalidades esportivas, consideradas clássicas na escola, como o futsal, vôlei, basquete e handball 
cedem espaço para uma educação em que sejam privilegiados temas diversificados e que, por sua vez, possam subsidiar os alunos de vivências motoras diversificadas ao longo da educação básica.

Nas práticas esportivas tradicionais, os elementos performáticos obrigam que a organização de tais práticas siga os ditames excludentes da aptidão física. Isso explica por que, em práticas dessa natureza, é comum a separação por categorias, decorrendo daí uma acentuada segregação. Já no caso dos esportes na natureza, o tempo e o espaço de prática é comum a todos, independentemente do seu nível de aptidão física, já que este critério não é um elemento que orienta prioritariamente essas práticas. Consequentemente, potencializa-se a aquisição pelos participantes de um ambiente de convívio harmonioso, entre as pessoas de diferentes sexos e idade, tornando-se, portanto, uma relação intergeracional (DIAS, 2004).

Sobre o valor educativo do esporte de aventura como conteúdo das aulas de Educação Física escolar têm-se aspectos motivacionais como o ambiente diversificado de práticas, tendo como eixo norteador o risco e fortes sensações. Esses elementos, comuns ao esporte de aventura, podem configurar-se como estímulo às sensibilidades corporais dos alunos possibilitando-os a partir do (re) encontro com as sensações corporais, experimentando e sentindo o próprio corpo em meio às fortes emoções e o risco em um mundo que, a cada vez mais, se centra na estimulação áudio visual. (BRUHNS, 2000; TRINDADE, 2001). Sobretudo, as aulas de Educação Física escolar precisam ser integradas aos princípios escolares e estes às condutas que conduzam ao desenvolvimento humano dentro de padrões morais aceitos em determinada sociedade. Além de considerar os conteúdos tradicionalmente trabalhados pelas escolas e trazidos pelos professores, os conteúdos da Educação Física escolar podem e devem ser ampliados com a diversidade contemporânea de alunos que são produtores e transmissores de cultura atendendo aos seus interesses considerados como conteúdos culturais emergentes (ARMBRUST; LAURO, 2010).

Dado ao fato de essas práticas corporais ocorrerem em diferentes ambientes naturais e pela crescente demanda que se impõe no contexto atual sobre o repensar nas ações ligadas às questões preservacionais do meio ambiente, elas podem propiciar elementos para se refletir e considerar uma abordagem da educação ambiental no âmbito da Educação Física escolar. Conforme afirma Dias (2004), a dimensão estética, contemplativa, presente nessas práticas, é que viabiliza de maneira lúcida e tangível sua articulação com a ética, imprescindível ao questionamento paradigmático reclamado pela educação ambiental.

Nesse sentido, as modalidades que compõem o esporte de aventura permitem que todos os saberes ambientais possam ser explorados na área urbana, pois meio ambiente pode ser retratado como o próprio ambiente em que nos situamos (PEREIRA; ARMBRUST, 2010).

Com base no tema transversal meio ambiente contido nos Parâmetros Curriculares Nacionais - PCNs para a Educação Básica, torna-se possível a transmissão de comportamentos de respeito e de preservação do meio natural, bem como da aprendizagem e vivências diferenciadas daquelas proporcionadas pelo esporte convencional como o futsal, vôlei, handebol e basquete que, infelizmente, ainda mantêm sua hegemonia nas aulas de Educação Física escolar. 
É notória a relação entre esporte de aventura e natureza, uma vez que o meio ambiente se apresenta como cenário para a realização das modalidades do referido segmento esportivo, suscitando uma interação entre o praticante e o respectivo meio.

Contudo, há que considerar as implicações decorrentes dessas atividades físicas no meio natural, pois usá-lo pode parecer conveniente e prazeroso, mas, sem os devidos cuidados, pode trazer sérios riscos de degradação e consequente ameaça à vida do planeta.

Assim, praias poluídas, áreas verdes devastadas e excesso de poluentes lançados na atmosfera são exemplos de problemas ambientais que afetam diretamente a prática de esporte de aventura.

Nas palavras de Guattari (2006), apesar de as formações políticas e instâncias executivas estarem começando a tomar consciência dos perigos que ameaçam o meio natural, elas o fazem ainda numa perspectiva tecnocrática, ao passo que a efetiva resposta à crise ecológica deverá ser gerada em escala planetária não só de forças visíveis, mas também dos domínios moleculares de sensibilidade, desejo e inteligência. Esse autor propõe uma articulação ético-política, a que chamou de ecosofia. Essa articulação envolveria os três registros ecológicos: o do meio ambiente, o das relações sociais e o da subjetividade humana.

No novo cenário que se delineia, a natureza não mais se limita a um objeto inanimado a ser explorado e sim como um projeto de parceria com o homem, imbuído de fatos da cultura e do fazer da sociedade (PÁDUA, 1992; PASSOS, 2004).

Ainda que permeadas pelas contradições e limitações, as práticas corporais na natureza que se manifestam nas diferentes modalidades do esporte de aventura podem apresentar-se como um poderoso aliado na dimensão preservacional do meio ambiente, num processo cujo ponto de partida se dará pela reestruturação do binômio homem-natureza. Trata-se de uma prática corporal que apresenta grande potencial educativo pelo fato de suscitar nos praticantes situações educativas em experiências pouco habituais, além de um forte caráter motivador, impregnada de fortes emoções, significado e intenção (PEREIRA; MONTEIRO, 1995).

Para essa reestruturação, a reflexão sobre as necessidades humanas e seus valores socialmente construídos pode ser o caminho para a formação de uma consciência ecológica e, consequentemente, a compreensão dos diferentes significados e implicações resultantes da interação dos seres humanos com o meio natural na contemporaneidade.

Para além das discussões relacionadas à preservação do meio ambiente, o esporte de aventura como conteúdo da Educação Física escolar propicia o trabalho com temáticas, discussões acerca de relações grupais ou subculturas (ARMBRUST; LAURO, 2010). Como pontua Uvinha (2001), nas aproximações grupais² para uma determinada prática, como é o caso do skate que, na busca por manobras que expressem radicalidade, no sentido de extrapolar a lógica social vigente, se percebe uma forma peculiar de comportamento que

2 O termo aproximações grupais apresenta-se neste estudo como o sentido de "tribo urbana", expressão que foi utilizada pela primeira vez pelo sociólogo francês Michel Maffesoli em seus artigos a partir de 1985. Maffesoli $(1995$, p. 17) O autor afirma que "as tribos reforçam um sentimento de pertença e favorecem uma nova relação com o ambiente social". 
envolve estilo de vestimenta, linguagens e condutas morais e éticas. Já entre os praticantes de parkour, é muito comum o processo de (re) significação do ambiente natural em que acontece a prática dessa modalidade. Muitas vezes, em locais que, para um não praticante, elementos da natureza como, por exemplo, um córrego, pedra ou árvore, que podem inspirar o desejo pela contemplação, para o praticante de parkour pode significar um obstáculo a ser transposto (CARVALHO; PEREIRA, 2008). Na mesma direção, se podem depreender elementos específicos por entre os praticantes da modalidade trekking de orientação que se fundamenta no trabalho em equipe, no contato com o meio natural, na ajuda ao próximo para passar um determinado trecho, caminhar em conjunto esperando o outro. Assim, abre-se caminho para o trabalho transdisciplinar, no âmbito escolar, como possibilidade de se analisar junto aos alunos informações sobre fauna e flora, os cuidados com os ambientes, bem como as condutas de mínimo impacto (PEREIRA: ARMBRUST, 2010).

Toda e qualquer proposta que envolva a inserção de novas temáticas no âmbito da escola, como é o caso dos esportes de aventura, suscita para além de uma consonância com os princípios almejados no projeto político pedagógico da escola, passa indubitavelmente pela necessidade de serem precedidas de reflexões a partir do conceito de conteúdo. Nessa perspectiva, o entendimento de conteúdo leva de forma irremediável à consideração das dimensões que permeiam o processo ensino aprendizagem de um dado conteúdo como a dimensão conceitual, atitudinal e procedimental (COLL, 2000; DARIDO, 2005). Como conteúdo da Educação Física escolar, o esporte de aventura leva às referidas dimensões.

Nessa direção, discute-se a seguir as dimensões do conteúdo (conceitual, procedimental e atitudinal) e sua interface no trato das diferentes modalidades de esporte de aventura na escola. De acordo com Pereira e Armbrust (2010) na dimensão conceitual podem ser desenvolvidos os aspectos históricos das modalidades, os locais de prática, os equipamentos, os objetivos e motivos de se praticar, bem como o entendimento do fator risco presente nas diferentes modalidades. No que se refere à dimensão procedimental, que trata do 'como fazer', podem ser desenvolvidas as técnicas de movimentos, as técnicas e princípios relacionados à segurança e bem estar do praticante, os processos pedagógicos e as adaptações necessárias do esporte para cada faixa etária e condições da escola. Finalmente, a partir da dimensão atitudinal, podem ser desenvolvidas a noção de regras, a ética dos esportes, o respeito às normas de segurança, a relação com situações de risco, a importância da cooperação entre praticantes no decorrer da prática de uma dada modalidade.

A partir de uma experiência vivenciada por Franco (2008) com a proposta de trabalho com a modalidade montanhismo para turmas do ensino médio, são descritas, a seguir, possibilidades de efetivação das dimensões para o referido conteúdo nas aulas de Educação Física escolar.

\section{Dimensão conceitual}

A dimensão conceitual como assinalam Coll et al. (2000) podem ser entendido como fatos, objetos ou símbolos que têm características comuns. Sua aprendizagem permite que 
o aluno seja capaz de utilizá-los para a interpretação, compreensão ou exposição de um fenômeno ou situação. Em outras palavras, como assinala Pozo (2000), o aluno aprendeu um conteúdo conceitual quando ele aprendeu o seu significado.

Ao se relacionar a dimensão conceitual ao esporte de aventura, é possível perceber, por exemplo, que as atividades pertencentes ao montanhismo, como escaladas, acampamentos, noções de sobrevivência e outras, são constantemente exploradas em filmes de aventura, documentários, produções literárias e pela mídia, ao divulgarem expedições de conquistas, explorações e expressões artísticas. Portanto, fazem parte de uma cultura histórico-artística presente em nossa sociedade e no imaginário das pessoas. Esses dados podem facilitar o trato com a dimensão conceitual deste conteúdo, seja numa forma de apresentação simples, ou nas montagens mais complexas.

Os alunos deverão montar técnicas verticais, como rapel e tirolesa, respeitando uma hierarquia de conceitos. Esses conceitos trabalhados podem ser ilustrados conforme o modelo simplificado a seguir: $O$ exemplo da Tirolesa - no $1^{\circ}$ ano do ensino médio. O professor monta a tirolesa, com o auxílio dos alunos, após apresentar conceitos e equipamentos. No $2^{\circ}$ ano, após a revisão dos conceitos, os alunos montam a estrutura, com o auxílio do professor e, no $3^{\circ}$ ano, os alunos montam tudo, com número certo de equipamentos específicos, num tempo estipulado pelo professor. E assim acontece com outras técnicas que envolvem conhecimentos e utilização de equipamentos específicos, no decorrer dos três anos do ensino médio.

\section{Dimensão atitudinal}

Os conteúdos atitudinais visam a mudança de comportamento e a formação do aluno como cidadão, ou seja, são conteúdos que contribuem para o desenvolvimento de valores, para a compreensão das normas de comportamento e as formas de conduta do indivíduo em relação a uma determinada situação. Configuram-se valores, normas e atitudes que devem estar presentes no trato de um dado conteúdo, possibilitando ao aluno a utilização do conhecimento adquirido não só no desenvolvimento das aulas, mas também em seu cotidiano (SARABIA, 2000).

Em se tratando de um conteúdo de pouca divulgação no Brasil, quando comparado aos esportes tradicionais trabalhados na escola, como futsal, handebol, basquete e vôlei, tem-se presente uma boa oportunidade para se retomarem discussões relevantes como: cooperação, cuidados com o próprio corpo e com o do colega, superação de limites pessoais, medo, confiança e autoconfiança, entre outros. A simples realização das tarefas de aula já demonstraria vários desses atributos e a emissão de juízos sobre as condutas de todos os envolvidos. Porém, com a efetivação das discussões acerca das sensações vivenciadas, da resolução dos problemas e de quais as perspectivas de utilização das técnicas, esse conteúdo fica muito interessante para a adequação escolar. De preferência, é o professor que testará a montagem das técnicas verticais, como a tirolesa, por exemplo, se tornando referência, demonstrando confiança nesta técnica de transposição e no trabalho dos alunos. 
Como envolve uma série de conceitos e procedimentos, os alunos devem mostrar empenho, organização, cuidado com os materiais e cooperação na realização das tarefas. As superações de limites pessoais aparecem com nitidez nessa atividade. O medo de altura, liderança, autoconfiança, timidez, vergonha, entre outros, são escancarados pelos alunos e deverão ser trabalhados pelo professor.

\section{Dimensão procedimental}

A dimensão procedimental pode ser entendida como um conjunto de ações e decisões organizadas que permitem trabalhar com o aluno sua capacidade de agir de maneira eficaz (COLL; VALLS, 2000). Esses autores ressaltam ainda que os conteúdos procedimentais envolvem ações e decisões externas ou internas, uma vez que podem estar presentes na ação corporal ou nas representações, respectivamente. Historicamente, tendo em vista a formação técnica que ainda parece prevalecer no âmbito pedagógico da Educação Física, dentre as dimensões do conteúdo, a procedimental tem-se sido a mais latente na prática de intervenção do professor nesse componente curricular.

Essa dimensão refere-se às vivências desenvolvidas pelos alunos no transcurso das aulas, desde as mais simples e possíveis em qualquer estrutura escolar, até aquelas que exigem equipamentos e conhecimentos profissionais. As ações responsáveis para se atingir as metas da aula devem ser precisas, caso contrário, não se cumprirão as vivências, efetivamente. Montar toda a estrutura requer, além de disciplina e organização, uma dose de coordenação e de habilidades gerais e específicas. A vivência das técnicas estimula a percepção sensorial e a utilização de vários grupos musculares importantes, aliados a uma boa comunicação entre todos os envolvidos.

Vale ressaltar que, no âmbito do processo ensino aprendizagem, as dimensões do conteúdo podem ser trabalhadas de maneira inter-relacionada, no entanto, tendo em vista as diferentes fases e/ou níveis de aprendizado em que o aluno se encontra, o professor poderá dar uma ênfase maior a uma dimensão. Nas palavras de Zabala (1998), somente através do conhecimento, da identificação e de possíveis implicações existentes entre as dimensões do conteúdo é que o professor será capaz de realizar este trabalho e assim, atender as necessidades de seus alunos.

Com vistas a ampliar a percepção do professor quanto à efetivação das dimensões dos conteúdos no trato do esporte de aventura nas aulas de Educação Física, será apresentado um quadro com outras modalidades. 


\begin{tabular}{|c|c|c|c|}
\hline \multicolumn{4}{|c|}{ DIMENSÕES DO CONTEÚDO } \\
\hline Modalidades & Conceituais & Procedimentais & Atitudinais \\
\hline Orientação & $\begin{array}{l}\text {-Histórico da modalidade } \\
\text {-Entender o equipamento } \\
\text {-Acessórios e logística } \\
\text {-Locais de prática } \\
\text { (elaboração de pistas nos } \\
\text { morros da região) } \\
\text {-Tipos de bússolas } \\
\text {-Leituras de mapas } \\
\text { (regionais) } \\
\text {-Ângulos e graus }\end{array}$ & $\begin{array}{c}\text {-Deslocamento e } \\
\text { contagem de passos } \\
\text {-Terrenos de diferentes } \\
\text { dimensões } \\
\text {-Deslocamentos com } \\
\text { diferentes graus de } \\
\text { dificuldade } \\
\text {-Passagem por } \\
\text { pontos acidentados } \\
\text { (constituição do terreno } \\
\text { local) } \\
\text {-Corrida de regularidade }\end{array}$ & $\begin{array}{c}\text {-Motivação em } \\
\text { praticar } \\
\text {-Reconhecimento } \\
\text { dos morros, trilhas e } \\
\text { acessos locais } \\
\text {-Assimilação das } \\
\text { passagens. } \\
\text {-Cuidados com o } \\
\text { equipamento } \\
\text {-Cuidados com o } \\
\text { meio natural e com a } \\
\text { segurança individual } \\
\text {-Afetividade e } \\
\text { companheirismo } \\
\text {-Sensações e emoções }\end{array}$ \\
\hline Trekking & $\begin{array}{l}\text {-Histórico da modalidade } \\
\text {-Locais de prática } \\
\text {-Interpretar a geografia local. } \\
\text {-Tipos de terreno } \\
\text {-Tipos de calçados } \\
\text {-Compreender aparelhos de } \\
\text { localização (GPS) }\end{array}$ & $\begin{array}{l}\text {-Caminhar em trilha } \\
\text { aberta e lisa } \\
\text {-Caminhar em trilha } \\
\text { fechada (em meio à } \\
\text { vegetação) } \\
\text {-Caminhada em costeira } \\
\text { (rochas à beira mar) } \\
\text {-Caminhada em rios }\end{array}$ & $\begin{array}{c}\text {-Cuidados ao abrir } \\
\text { trilhas } \\
\text {-Responsabilidade } \\
\text {-Afetividade e } \\
\text { companheirismo } \\
\text {-Respeito pelo } \\
\text { ambiente natural e } \\
\text { seus obstáculos } \\
\text {-Expectativas }\end{array}$ \\
\hline Canoagem & $\begin{array}{l}\text {-Histórico da modalidade } \\
\text {-Tipos de embarcação } \\
\text {-Tipos de remos e } \\
\text { equipamentos de segurança } \\
\text {-Locais de prática } \\
\text {-Acessórios } \\
\text {-Meteorologia (condições } \\
\text { climáticas, formação de } \\
\text { ondas e ventos etc) }\end{array}$ & $\begin{array}{c}\text {-Posição fundamental } \\
\text {-Deslocamentos na água } \\
\text {-Tipos de remada e giros } \\
\text {-Saída da praia e retorno } \\
\text { à praia } \\
\text {-Passagens de } \\
\text { arrebentação } \\
\text {-"Surfar" as ondas }\end{array}$ & $\begin{array}{c}\text {-Assimilação dos } \\
\text { exercícios } \\
\text {-Cuidado com os } \\
\text { materiais } \\
\text {-Segurança na água } \\
\text {-Sensações e emoções } \\
\text {-Responsabilidade e } \\
\text { companheirismo } \\
\text {-Dificuldades } \\
\text { apresentadas }\end{array}$ \\
\hline Acampamento & $\begin{array}{l}\text {-Conhecer os equipamentos } \\
\text {-Acessórios e logística } \\
\text {-Nutrição específica } \\
\text {-Primeiros socorros básicos } \\
\text {-Cuidados com o ambiente } \\
\text { (lixo, fogo, etc) }\end{array}$ & $\begin{array}{c}\text {-Montagem de } \\
\text { acampamentos } \\
\text {-Locais ideais, abrigos, } \\
\text { bivaques } \\
\text {-Organizar o local de } \\
\text { acampamento } \\
\text {-Organizar a barraca } \\
\text {-Organizar a mochila } \\
\text {-Divisão de tarefas }\end{array}$ & $\begin{array}{l}\text {-Cuidado com os } \\
\text { materiais. } \\
\text {-Responsabilidade } \\
\text {-Companheirismo } \\
\text {-Dificuldades } \\
\text {-Simbiose com a } \\
\text { natureza (desfrutar } \\
\text { sem prejudicar) }\end{array}$ \\
\hline
\end{tabular}

Fonte: Pereira e Marinho (2013). 
Nesta perspectiva, o trato com as modalidades de esporte de aventura pelo viés da multidimensionalidade de prática corporal que ocorre no meio natural abre possibilidades de se desenvolver no educando uma atitude de observador atento às mudanças, traçando possíveis relações que o meio estabelece com o organismo durante uma prática; e, também, uma atitude no cotidiano que busque minimizar as marcas deixadas pelo homem no meio ambiente. É possível, ainda, ampliar a capacidade dos educandos de perceber a natureza, de sentir-se parte dela, de responsabilizar-se pela sua manutenção.

Nesta perspectiva que sinaliza potencialidades para uma prática educativa pela vertente do esporte de aventura no âmbito escolar, visando à minimização dos efeitos negativos da ação do homem sobre os diferentes ambientes naturais, questiona-se: é oportuno considerar, dentre as finalidades da Educação Física, a promoção da saúde e da qualidade de vida do sujeito, e refletir sobre a viabilidade da promoção e manutenção da saúde e da qualidade de vida sem, no entanto, sopesar a qualidade do ambiente no qual essas finalidades são efetivadas? Desta forma, a dimensão preservacional, de forma direcionada daquilo que busca a Educação Física na vida do sujeito, não se restringe tão somente à vertente do esporte de aventura. Haja vista os diferentes ambientes naturais em que se desenvolvem as práticas de aventura, bem como a grande relevância da área de Educação Física, tem a dimensão preservacional entendida aqui como um processo de aprendizagem permanente baseado no respeito a todas as formas de vida. Essa dimensão, se praticada, nas aulas de Educação Física, pelo viés do esporte de aventura, preferencialmente no âmbito interdisciplinar, contribui para a afirmação de valores e ações que podem contribuir para a transformação humana e social e para a preservação do meio ambiente (BARROS, 2000).

A conexão dessas práticas corporais de aventura aos objetivos educacionais do sistema escolar pode favorecer o desenvolvimento humano em seus diversos aspectos, por envolverem processos pedagógicos específicos catalisadores de competências cognitivas, psicomotoras e socioafetivas sendo capazes de fomentar novas atitudes de espectro interdisciplinar (PEREIRA; MONTEIRO, 1995).

\section{CONCLUSÕES}

A proposta apresentada no presente estudo contempla o esporte de aventura como possibilidade de conteúdo de intervenção na realidade concreta que se coloca nas aulas de Educação Física escolar nessa contemporaneidade, vislumbra, no limite de seu potencial, superar o enfoque de ensino aprendizagem das práticas corporais, puramente técnico, rumo a um projeto de apropriação mais ampla, questões que perpassam a construção e apreensão do conhecimento pelo aluno na formação básica.

O trato das diferentes modalidades que compõem o esporte de aventura nas aulas de Educação Física escolar, vislumbrada nessa investigação considerou como viés de intervenção as dimensões conceitual, procedimental e atitudinal que perpassam o processo de ensino aprendizagem do conteúdo na ambiência formal. 
Esse entendimento busca, sobretudo, ampliar o conceito de esporte de aventura enquanto conteúdo a ser inserido e trabalhado na escola numa dimensão que não contemple apenas as capacidades motoras, mas as demais capacidades que possibilite ao aluno no decorrer da educação básica reproduzir, transformar e partilhar as diversas formas de manifestações corporais que caracterizam a Educação Física como área do saber. Tal construção e apreensão fundamentam-se nas correlações entre as práticas corporais e as dimensões em que se estruturam o ambiente social.

Acredita-se no envolvimento e na contribuição da Educação Física como componente curricular para oferecer uma aprendizagem mais significativa e mais efetiva aos alunos no processo educacional desenvolvido nas escolas.

Tem-se, com isso, a crença de que a busca por elementos com potencial para um currículo escolar alternativo para Educação Física é, acima de tudo, uma atitude de não conformismo, por parte dos atores envolvidos na ação educativa. A própria realidade nas escolas evidencia a necessidade de propostas e movimentos para implementar o processo educacional nos diferentes segmentos que compõem a educação básica e que, por sua vez, possam atendem as necessidades de um modelo de formação para a sociedade atual.

\section{REFERÊNCIAS}

ARMBRUST, I.; LAURO, F. A. A. O skate e suas possibilidades educacionais. Motriz. Rio Claro - SP, v. 16, n. 3, 2010. Disponível em: < http://www.scielo.br/scielo.php?pid= S198065742010000300028\&script = sci_arttext $>$. Acesso em: 12 mar. 2013.

BARROS, M.A. Outdoor Education: uma alternativa para a educação ambiental através do turismo de aventura. In: SERRANO, C. (org.). A educação pelas pedras: ecoturismo e educação ambiental. São Paulo: Chornos, 2000.

BRASIL, Parâmetros Curriculares Nacionais: $3^{\circ}$ e $4^{\circ}$ ciclos do Ensino Fundamental: Educação Física. Brasília/DF: MEC/SEF, 1998.

BRUHNS, H. T. Esporte e natureza: o aprendizado da experimentação. IN SERRANO, Célia. (Org.) A educação pelas pedras: ecoturismo e educação ambiental. São Paulo: Chronos, 2000.

CBSK, Confederação Brasileira de Skate. Apresenta informações e dados sobre o esporte. Disponível em http://www.cbsk.com.br/asp/dados. Acesso em: 21 mar. 2013.

CARDOSO, A. R.; SILVA, A.; FELIPE, G. R. A educação pela aventura: desmistificando sensações e emoções. Motriz, Rio Claro, v. 12, n. 1, p. 77-87, jan./abr. 2006.

CARVALHO, R. G.; PEREIRA, A. P. Percursos alternativos: o Parkour enquanto fenômeno (sub)cultural. Revista Portuguesa de Ciências do Desporto. Portugal, Lisboa, v. 8, n. 3, p. 427-440, 2008.

COICEIRO, G. A. O imaginário social de aventureiros do extremo: o universo simbólico dos praticantes de provas de ultra-resistência. 136 folhas. Tese (Doutorado em Educação Física). Programa de Pós-Graduação em Educação Física. Universidade Gama Filho, Rio de Janeiro, 2007. 
COLL, C. Os conteúdos na EFE. In: COLL, C. et al. Os conteúdos na reforma: ensino aprendizagem de conceitos, procedimentos e atitudes. Porto Alegre: Artmed, 2000.

COLL, C.; VALLS, E. A aprendizagem e o ensino dos procedimentos. In: COLL, C. e colaboradores. Os conteúdos na reforma: ensino e aprendizagem de conceitos, procedimentos e atitudes. Porto Alegre, RS: Artmed, 2000. cap. 2, p. 73-118.

COSTA, V. L. M. Esportes de aventura e risco calculado na montanha: um mergulho no imaginário. São Paulo: Manole, 2000.

DARIDO, S.C; RANGEL, I. C. A. EF no ensino superior: EF na Escola. Implicações para a prática pedagógica. Rio de Janeiro: Guanabara Koogan, 2005.

DIAS, C. A. G. Lazer e esportes na natureza face a educação ambiental: entre o possível e o necessário. In.: Seminário o lazer em debate, V., 2004. Rio de Janeiro. Anais... (CD-ROM).

FRANCO, L. C. P. Atividades físicas de aventura na escola: uma proposta pedagógica nas três dimensões do conteúdo. 133 folhas. Dissertação (Mestrado em Ciências da Motricidade). Programa de Pós- Graduação em Ciências da Motricidade. Universidade Estadual Paulista, Rio Claro, 2008.

GUATTARI, F. As três ecologias. $17^{\mathrm{a}}$ ed. Campinas, SP: Papiros, 2006.

LAKATOS, E. M.; MARCONI, M. A. Metodologia do trabalho científico. $7^{\mathrm{a}}$ ed. São Paulo: Atlas, 2007.

MAFFESOLI, M. A contemplação do mundo. Porto Alegre: Artes e Ofícios, 1995.

MARINHO, A.; BRUHNS, H. T. Turismo, lazer e natureza. São Paulo: Manole, 2003.

MARINHO, A.; SCHWARTZ, G. M.; LETIZIO, J. B. Atividades de Aventura no contexto acadêmico. Anais do II Congresso Internacional de Educação Física e Motricidade Humana e VIII Simpósio Paulista de Educação Física. Motriz Revista de Educação Física UNESP Rio Claro (SP), nov. 2001.

PADUA, J. A. Ecologia e política no Brasil. 2a ed. Rio de Janeiro: Espaço e Tempo, 1992. PASSOS, K. C. M. Caminhando nas trilhas do reencantamento da natureza: uma ecologia do corpo sagrado e errante. 298 f. Tese (Doutorado em Educação Física). Programa de Pós-Graduação em Educação Física. Universidade Gama Filho, Rio de Janeiro, Brasil, 2004.

PEREIRA, F. R.; MARINHO, A. Aventura e educação ao ar livre: uma alternativa à educação formal na comunidade do Perequê (Guarujá, SP) In.: PEREIRA, D. W. (Org.) Atividades de aventura: em busca do conhecimento. Várzea Paulista, SP: Fontoura, 2013.

PEREIRA, D. W.; ARMBRUST, I.; RICARDO, D. P. Esportes radicais, de aventura e ação: conceitos, classificações e características. Revista Corpoconsciência, São Paulo, v. 12, n.1, p. 35-56, jan/jun. 2008.

PEREIRA, D. W.; ARMBRUST, I. Pedagogia da aventura. Jundiaí, SP: Fontoura, 2010.

PEREIRA, J. M.; MONTEIRO, L. R. Atividades Físicas de exploração da natureza - em defesa do seu valor educativo. Revista Horizonte Científico. Uberlândia, v. 69, n. 3, p. 111-116, mai. 1995.

POZO, J. I. A aprendizagem e o ensino de fato e conceitos. In: COLL, C. e colaboradores. Os conteúdos na reforma: ensino e aprendizagem de conceitos, procedimentos e atitudes. Porto Alegre, RS: Artmed, 2000. cap. 1, p. 17-72. 
SARABIA, B. A aprendizagem e o ensino de atitudes. In COLL, C. e colaboradores. Os conteúdos na reforma: ensino e aprendizagem de conceitos, procedimentos e atitudes. Porto Alegre, RS: Artmed, 2000, p. 119-178.

TRINDADE, A. L. Olhando com o coração e sentindo com o corpo inteiro no cotidiano escolar. In.: TRINDADE, A. L. da. (Org.) Multiculturalismo: mil e um faces da escola. Rio de Janeiro: DP\&A, 2001.

UVINHA, R. R. Juventude, lazer e esportes radicais. São Paulo. Manole, 2001.

ZABALA, A. A prática educativa: como ensinar. Porto Alegre: Artmed, 1998.

\title{
ADVENTURE SPORT AS POSSIBLE CONTENT IN PHYSICAL EDUCATION CLASSES
}

\begin{abstract}
This study aimed to investigate possibilities to work the different adventure sport modalities as content of Physical Education at school. From a literature review, strengthens the belief that the search for elements with the potential for an alternative curriculum for Physical Education is, above all, an attitude of non-conformism, by the actors involved in the educational activity. Reality itself in schools highlights the need for proposals and moves to implement the educational process in the different segments of basic education. Certainly, reflection and debate on this theme configured to fundamental procedures so that the possibilities can be realized in the Physical Education classes.
\end{abstract}

Keywords: School; Physical Education; Adventure Sport

\section{DEPORTE DE AVENTURA COMO EL CONTENIDO POSSIBLE EN CLASES DE EDUCACIÓN FÍSICA EN LA ESCUELA}

\section{RESUMEN}

Este estudio investiga las posibilidades para el tratamiento de diferentes tipos que componen el deporte de aventura como el contenido de la educación física en la escuela. A partir de una revisión de la literatura especializada, refuerza la creencia de que la búsqueda de elementos con el potencial de un currículum alternativo para la educación física es, sobre todo, una actitud de no conformidad por parte de los actores que participan en actividades educativas. La realidad misma en las escuelas pone de relieve la necesidad de propuestas y se mueve para poner en práctica el proceso educativo en los diferentes segmentos que conforman la educación básica. Ciertamente, la reflexión y el debate sobre ese tema configuran los procedimientos básicos para que las posibilidades se pueden realizar en el ambiente de las clases de Educación Física.

Palabras clave: Escuela; Educación Física; Deporte de Aventura 